\title{
Mutant strains of SARS-CoV-2 are more prone to infect obese patient: a review
}

\author{
Somorjit Singh Ningombam (D) - Rakesh Kumar (D) P Pranay Tanwar (D)
}

Received: 20 August 2020 / Accepted: 16 January 2021 / Published online: 17 February 2021

(C) Springer-Verlag GmbH, AT part of Springer Nature 2021

\begin{abstract}
Summary The current review critically analyzes obesity as an important risk factor for increased predisposition towards coronavirus disease 2019 (COVID19), its severity and causal death in current pandemic. Countries with higher prevalence of exposed obese individuals experienced the highest number of mortalities. The analysis also proved that individuals having more adipose tissue in body have a higher level of angiotensin-converting enzyme 2 (ACE2), which is identified as functional receptor for COVID-19. Therefore, obese individuals are worse in condition because of a higher presence of adiposity increases the number of ACE2 expressing cells. Furthermore, in silico interactions of ACE2 and different variants of coronavirus 2 (CoV-2) spike S1 protein suggest that mutant strains are more infectious than wildtype as they bind to host ACE2 protein with high binding affinities. Certain specific cancers including cervical cancer, pancreatic and rectal adenocarcinomas have more expression of such receptors and pose additional risk to already immunocompromised cancer patients. This review emphasizes obesity, as the covert risk factor of COVID-19 infection and sensitizes about of calorie restrictions, immunity building and preventive measures.
\end{abstract}

\footnotetext{
S. S. Ningombam · R. Kumar

Additional Professor Dr P. Tanwar ( $₫)$

Laboratory Oncology Unit, Dr. B.R.A. Institute Rotary Cancer

Hospital, All India Institute of Medical Sciences, 110029 New Delhi, India

pranaytanwar@gmail.com

S. S. Ningombam

somoangomcha@gmail.com

R. Kumar

rakeshkapoor.aiims@gmail.com
}

Keywords COVID-19 - Angiotensin-converting enzyme 2 - Comorbidities · Spike protein · Proteinprotein interaction

\section{Introduction}

Coronavirus disease 2019 (COVID-19) is currently a breakneck pandemic which almost all the nations are suffering from right now worldwide. Coronavirus belong to the Coronaviridae family, Orthocoronavirinae subfamily and the order Nidovirales. The $\alpha$-coronavirus, $\beta$-coronavirus, $\gamma$-coronavirus, and $\delta$-coronaviruses belong to the Orthocoronavirinae subfamily [1]. Normally, coronaviruses cause zoonotic infections; however, in the last decades they have shown evidence of infections among human as well [2]. The evidence of the coronavirus lethality, when they cross the barrier, and infect human beings was proved by the epidemic of severe acute respiratory syndrome (SARS) and Middle East respiratory syndrome (MERS) in 2002 and 2012, respectively [2]. The two viruses SARS-CoV and MERS-CoV belong to the $\beta$-coronavirus genus [3]. Recently, in late 2019, a novel flu-like coronavirus (SARS-CoV-2) closely linked to SARS and MERS was reported in China [4, 5] with the evidence of transmission between human to human having close contacts [6]. The genome of coronaviruses is a single stranded positive sense RNA, which is typical genome structure of $\beta$-coronavirus similar to the earlier SARS and MERS coronaviruses [7]. More than $82 \%$ similarity was observed between the SARS-CoV-2 and SARS-CoV, hence the name SARS-CoV-2 was given [8, 9]. The World Health Organization (WHO) declared COVID-19 to be a public health emergency of international concern (PHEIC) and declared it as pandemic on 30 January 2020. To date, the line of treatment is basically symptomatic as there is no confirmed treatment and vaccine for this illness [10-14]. 
The comorbidities associated with COVID-19-related deaths are all found under the category of obesity comorbidities, such as hypertension, type 2 diabetes, cardiovascular diseases. This article is focused to understand the crosstalk between angiotensinconverting enzyme 2 (ACE2) and SARS-CoV-2 spike protein and positive association between obesity with mortality and morbidities of the disease.

\section{Material and methods}

\section{Literature search and selection}

The articles were searched in online databases, including PubMed, Google Scholar and Web of Science, from March 2020 to May 2020 by using the following keywords: SARS-CoV-2, COVID-19, obesity, clinical characteristics and comorbidities. There were no restrictions in language and study population in the online search of literature and only the online published literature was used for better accuracy of manuscripts available.

\section{Inclusion and exclusion criteria}

The manuscripts having elaborated study design, study population, patients diagnosed with COVID19 along with comorbidities associated with obesity were selected for analysis. There was no restriction in the sample size of the selected literature because of the limited number of research based on COVID-19 and obesity. Research findings based on newspaper and online sources, also without authentic publishers were excluded.

\section{Data extraction and quality assessment}

According to the inclusion and exclusion criteria, information on comorbidities, number of confirmed cases and death along with prevalence of obesity in the study were tabulated. For the COVID-19 updated cases and country-wise obesity prevalence percentages from the World Health Organization website was utilized. Variables were compared with the different manuscripts published from different countries from specific geographic locations.

\section{Interaction of host ACE2 and SARS-CoV-2 spike protein}

Experimentally solved structure of full length ACE2 in complex with receptor binding domain (RBD) of SARS-CoV-2 was taken from the protein data bank (PDB ID:6M17) which was resolved at $2.9 \AA$ resolution $[15,16]$. Targeted complex and mutated SARS-CoV-2 spike proteins were prepared in PyMOL (The PyMOL Molecular Graphics System, Version 1.3 Schrodinger, LLC). Structures were energy minimized in SwisPDB Viewer followed by protein-protein docking at ClusPro docking server [17-19]. All visualizations were made at PyMOL (PyMOL Molecular Graphics System, Version 1.3 Schrodinger, LLC) graphical system.

\section{Obesity and COVID-19}

A study conducted in Chinese population reported that among the SARS-CoV-2 infected old age patients with comorbidities have more severe course of COVID-19 compared to the patients of younger age and without comorbidities [20]. Among various comorbid conditions, cardiovascular diseases (CVD, $10.5 \%)$ contributed the highest fatality rate followed by diabetes mellitus $(7.3 \%)$, chronic respiratory diseases $(6.3 \%)$, hypertension $(6.0 \%)$ and cancer $(5.6 \%)$ [20]. The first study, which has revealed body mass index (BMI) data among the COVID-19 patients was from the Seattle region of Washington with a small sample size of 24 patients (3 normal categories; 7 overweight, 13 obese and 1 missing data); however, the sample sizes are very small for a meaningful statistical analysis, among them $85 \%$ of the obese patients required ventilation and $65 \%$ died compared to those patients without obesity in which $64 \%$ required ventilation and $36 \%$ died [21]. A well-known fact that an increase in adipose tissue has a strong association with CVD and diabetes mellitus, a high BMI might be

Table 1 Country-wise association studies of obesity and COVID-19

\begin{tabular}{|c|c|c|c|c|c|c|}
\hline Authors & Publication Year & Sample size & Country & Study Design & Phenotype & Association \\
\hline Lighter et al. [26] & 2020 & 3615 & United States of America & Retrospective analysis & Acute or critical care & Yes \\
\hline Qingxian et al. [23] & 2020 & 383 & China & Cross-sectional Study & Severe pneumonia & Yes \\
\hline Simonnet et al. [25] & 2020 & 124 & France & Retrospective cohort study & IMV & Yes \\
\hline Zheng et al. [27] & 2020 & 214 & China & Multi-center Study & MAFLD & Yes \\
\hline Zhou et al. [28] & 2020 & 327 & China & $\begin{array}{l}\text { Multi-center preliminary analy- } \\
\text { sis }\end{array}$ & MAFLD & Yes \\
\hline Huang et al. [29] & 2020 & 1 & China & Case study & Hypoventilation & Yes \\
\hline Petrilli et al. [24] & 2020 & 4103 & United States of America & Cross-sectional study & Hospitalization, IMV & Yes \\
\hline Bello-Chavolla et al. [30] & 2020 & 15529 & Mexico & Cross-sectional study & Diabetes, COVID-19 & Yes \\
\hline Bhatraju et al. 2020 [21] & 2020 & 24 & United States of America & Case study & Ventilation and death & Yes \\
\hline
\end{tabular}


an important risk factor for severe course of disease, especially pneumonia, a severe clinical condition of COVID-19 [22]. Among the 383 COVID-19 patients admitted in the Hospital of Shenzhen, China it was found that obese patient showed 2.42-fold increased odds of developing severe pneumonia, after adjusting for respective confounders [23]. Another study from New York City has shown that among 1103 COVID19 patients, individuals who have BMI $>40 \mathrm{~kg} / \mathrm{m}^{2}$ were the second strongest predictor of hospitalization, after old age [24]. A retrospective study from the University Hospital in Lille, France, reported the need for invasive mechanical ventilation among the COVID19 patients with a BMI $\geq 35 \mathrm{~kg} / \mathrm{m}^{2}$, independently of other comorbidities and disease severity increased with BMI [25]. Furthermore, different studies from various countries found consistent associations with obesity and multiple complications [26-30]. The possible parameters mediating this higher risk among overweight and obese patients could be impaired respiratory mechanics, increased airway resistance and impaired gas exchange, as well as other known pathophysiological characteristics of obesity, e.g. low respiratory muscle strength and lung volume [22, 31]. There are a limited number of studies reported to date in association with COVID-19 and obesity; some of the published articles are given in (Table 1).

\section{Comorbidities and clinical problems}

Obesity is a medical condition caused by multifactorial pathways and links with various comorbidities and clinical problems. With the difference of study population and study design there are various comorbidities and clinical conditions reported in association with obesity. Different research findings revealed various comorbidities associated with both general and central obesity cardiovascular and cere- brovascular diseases, type 2 diabetes, hypertension, gallstones, gastroesophageal reflux disease, malignancies, obstructive sleep apnea syndrome (OSAS), fatty liver disease, infertility, osteoarthritis, respiratory dysfunction, respiratory abnormalities, psychiatric conditions, polycystic ovarian syndrome in women and even increase the risk of certain type of cancer [32-34]. Obesity is a well-known risk factor for asthma patients. Obese individuals with asthma are extremely symptomatic and experience a poor quality of life, in spite of using high dose of corticosteroid drugs [35]. A lifeline cohort study in the Netherlands of a total of 89,332 participants showed a strong association of obesity and major depressive disorder (MDD) and anxiety disorder and further suggests to manage MDD, anxiety disorder and weight loss to improve mental health of the population [36]. Early onset, long duration, and excessive obesity aggravated the CVD risk and consequences [37]. Association studies between obesity and life expectancy have showed how early onset of obesity during adulthood was associated with a decrease in life expectancy of approximately 6-13 years [38, 39]. A study from the National Health Survey, USA reported that obesity during the early adulthood was not only associated with the reduction of life expectancy but also reduced number of lives free from diabetes and cardiovascular diseases in both sexes [40,41].

The features commonly associated with COVID19 are male sex, older age, CVD and diabetes; however, a Chinese study reported higher BMI to be more commonly found among nonsurvivors [42]. In a single-center retrospective study of Wuhan Jin YinTan hospital (China) it was found that most of the patients had organ damage, $67 \%$ acute respiratory distress syndrome (ARDS), 29\% acute kidney injury, $23 \%$ with cardiac injury, $29 \%$ with liver dysfunction, and $2 \%$ with pneumonia [43]. A nationwide analysis
Fig. 1 Comorbidities and clinical features shared between obesity and COVID19

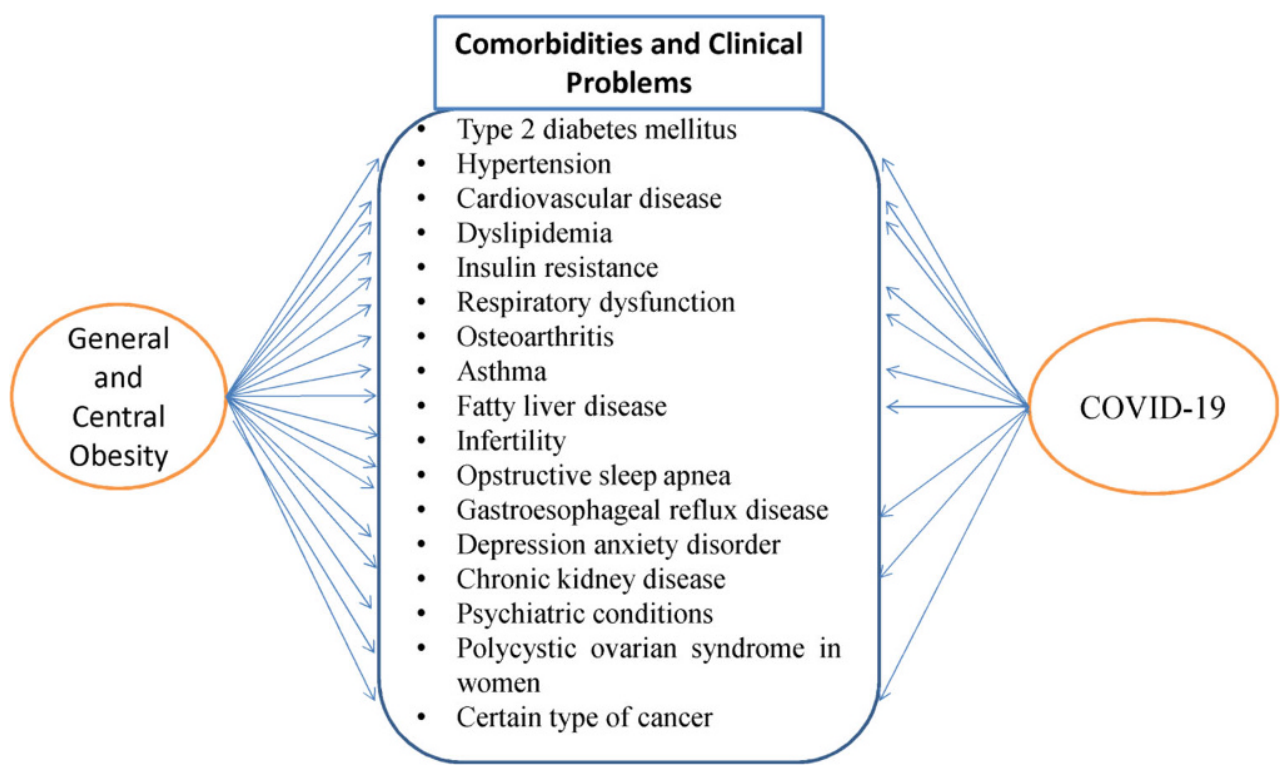


of COVID-19 among cancer patients revealed that individuals with cancer are more susceptible to infection compared with noncancer patients because of their systematic immune suppressive state caused by the malignancy and anticancer treatment, such as chemotherapy or surgery [44]. Patients with chronic respiratory syndrome especially chronic obstructive pulmonary diseases (COPD) and asthma would be at increased risk of SARS-CoV-2 infection and more severe consequences of COVID-19 [45]. The prevalence of COVID-19 patients who are already diagnosed with diabetes is much higher in number than the estimated national prevalence [45]. In an Italian population studies, diabetes may not increase the risk of SARS-CoV-2 infection but could worsen the disease outcome [46]. A meta-analysis done by Jiang et al. showed that among the severe COVID-19 cases, comorbidities like hypertension $(21 \%)$, diabetes $(9.7 \%)$, CVD $(8.4 \%)$, respiratory system disease $(1.5 \%)$, are commonly involved compared with non-severely ill patients [47]. Details of the comorbidities and clinical problem shared between obesity and COVID-19 are given in Fig. 1.

\section{Obese patients are worse than lean patients}

The ACE2 is a membrane-bound aminopeptidase and identified as functional receptor for coronaviruses including SARS-CoV and SARS-CoV-2 infections. The spike protein of the virus triggered binding to the ACE2 [48]. The expression level of ACE2 between obese and non-obese individuals is almost similar, albeit obese individuals are worse in condition because of higher presence of adiposity increases the number of cells expressing ACE2 [49]. In two different studies, ACE2 expression level in tissues was consistently found to be higher in the heart, kidney, testis, gallbladder, adipose tissue, intestine and bladder compared to that of lungs $[49,50]$. Another cancer database analysis showed that ACE2 expression levels are found to be higher among the five types of cancer, i.e. cervical squamous carcinoma and endocervical adenocarcinoma (CECS), pancreatic adenocarcinoma, rec- tum adenocarcinoma, kidney renal papillary cell carcinoma and kidney renal cell carcinoma than the adjacent tissues [49].

Chronically, obese individuals possess higher concentrations of leptin (a pro-inflammatory adipokine) and lower adiponectin (an anti-inflammatory adipokine). Furthermore, dysregulation of the adipokine production as a result of adipose tissue expansion can lead to local or systematic effects on inflammatory responses, thus contributing to the imitiation and progression of obesity-induced metabolic and cardiovascular complications [51]. At the time an antigen enters obese individuals, obesity-related chronic inflammation causes lesser macrophage activation and pro-inflammatory cytokine upon microphage stimulation [52]. The decreased macrophage activation after an antigen present in an obese individual explains the poor vaccination success, antiviral-resistant and variants escape from vaccine among the obese population [53, 54]. In addition, obese individuals are experiencing with physically inactive and sedentary lifestyle further impaired immune response against microbial agents at different stages [55, 56]. Obese individuals with influenza have higher chances to spread the disease because the virus stays for a longer period of time compared to normal individuals [57]. Above that, obese microenvironment enhances the exposure of novel virulent virus strains because of the decreased interferon reponses and increased viral replication [58].

\section{Mutated strains of SARS-CoV-2 have higher tendency of infection than wild type}

The SARS-CoV-2 interacts with host ACE2 protein through spike S1 subunit of S protein. The binding of host and viral protein is accomplished through the interaction of ectodomain also known as RBD with peptidase (PD) domain of host ACE2 receptor [59]. The ACE2 is comprised of PD of 19-615 amino acids and C-terminal collectrin-like domain (CLD) of 616-768 amino acids (Fig. 2a). The RBD of CoV-2 spike protein consists of numerous sheets and large
Fig. 2 Tertiary structure of a human ACE2 and $\mathbf{b}$ RBD of SARSCoV2 spike protein. ACE2 and RBD are shown as publication and tint color cartoon modes, respectively. Mutant residues are shown in red sticks

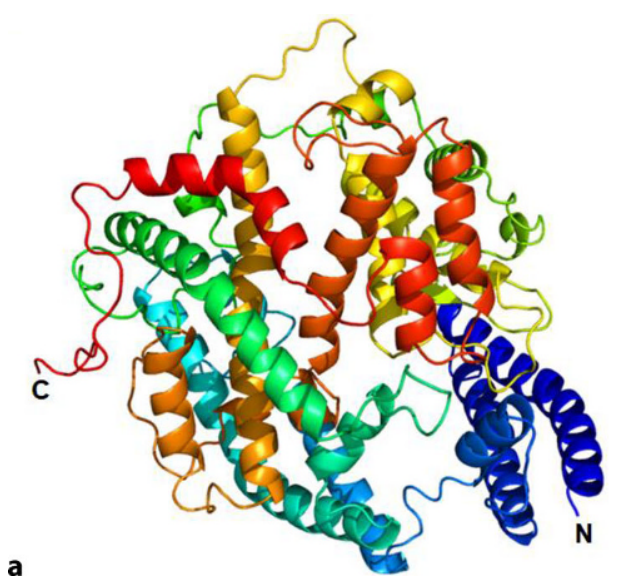

b 

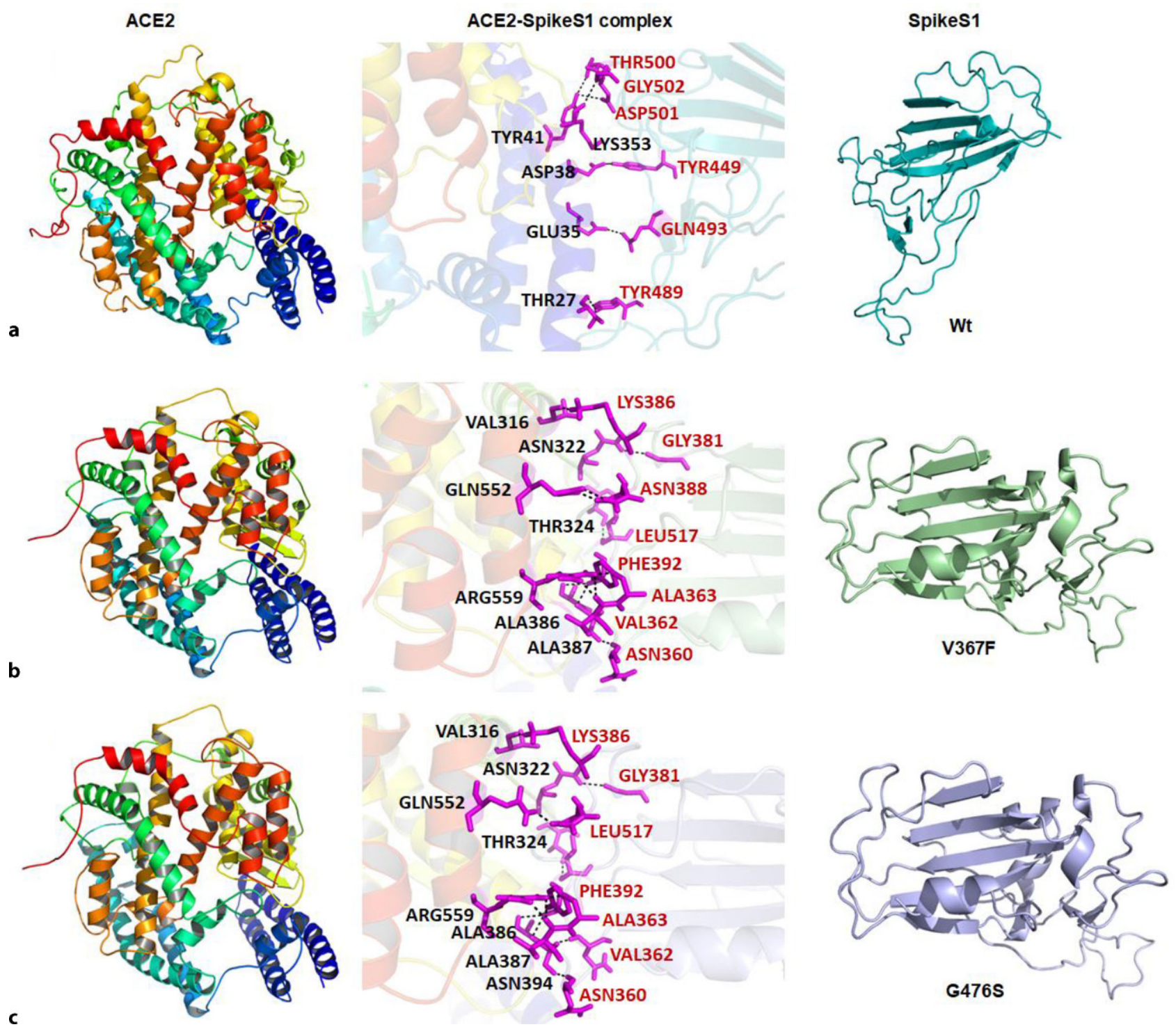

Fig. 3 Protein-protein interaction analyses of a ACE2 and wildtype spike S1 complex, b ACE2 and spike S1 V367F mutant complex and c ACE2 and spike S1 G476S mutant complex. ACE2 is shown in publication cartoon mode while WT, V367F, and G476S mutants are shown in teal, pale green and

light blue color, respectively. Interacting residues are shown in stick with magenta color and $\mathrm{H}$-bonds are shown in black. Interacting residues of $\mathrm{ACE} 2$ and spike $\mathrm{S} 1$ residues are labelled in three letter amino acid codes with black and red color, respectively

loop regions (Fig. 2b). Polar interactions provide the interface between SARS-CoV-2 and ACE2. Extended loop region of RBD interacts largely with helix 1 and slightly with helix 2 of ACE2. Residues located at both $\mathrm{N}$-terminal and C-terminal side of helix 1 interact with residues found in extended loop and other regions of RBD. The T27 (threonine), E35 (glutamate), D38 (aspartate), Y41 (tyrosine) and K353 (lysine) of ACE2 interact with Y489, Q493 (glutamine), Y449, T500, N501 (asparagine) and G502 (glycine) of RBD, respectively (Fig. 2a). Recent study in different population of Europe, China and the USA has reported numerous mutated strains of SARS-CoV-2 that are more contagious than wild type, and arise due to mutations in RBD of spike protein. The mutations in spike protein such as V367F (valine 367 to phenylalanine), G476S (glycine 476 to serine) and V483A (valine 483 to alanine) have been reported from European and US populations [60]. Recently, a new strain from B.1.1.7 lineage emerged from the United Kingdom, in which asparagine 501 of RBD domain of spike S1 protein is mutated to tyrosine (N501Y) and is more transmissible than established lineages (Fig. 2b; [61]). Apart from these mutations, some other mutations are also reported in other regions of spike protein that are not directly involved in viral interaction with host ACE2 receptor protein.

In our analyses, we found that mutations in RBD increase the affinity of SARS-CoV-2 interaction with host ACE2. Protein-protein interaction analysis of 
ACE2

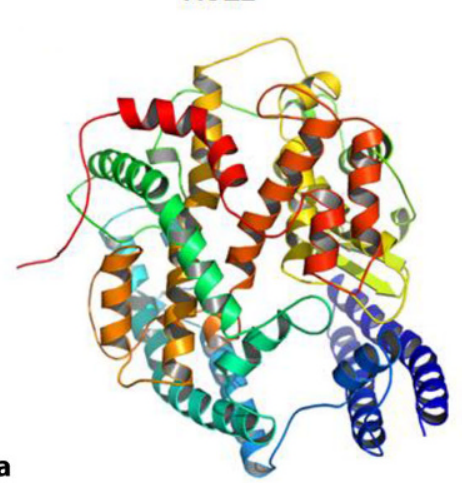

a

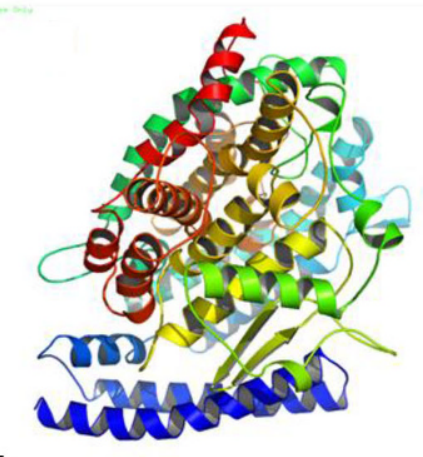

ACE2-Spikes1 complex
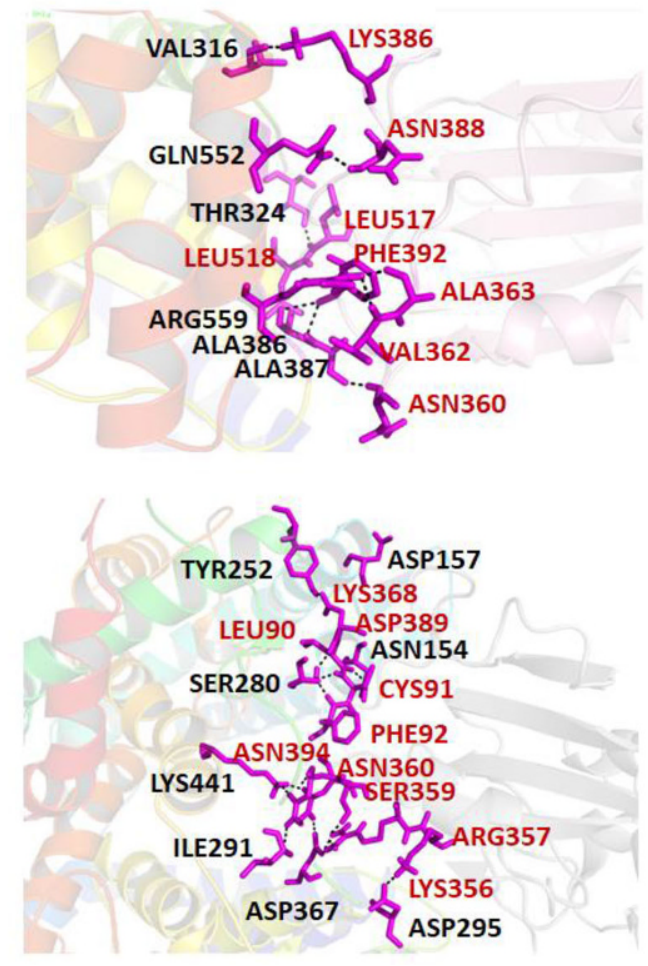

Spikes1
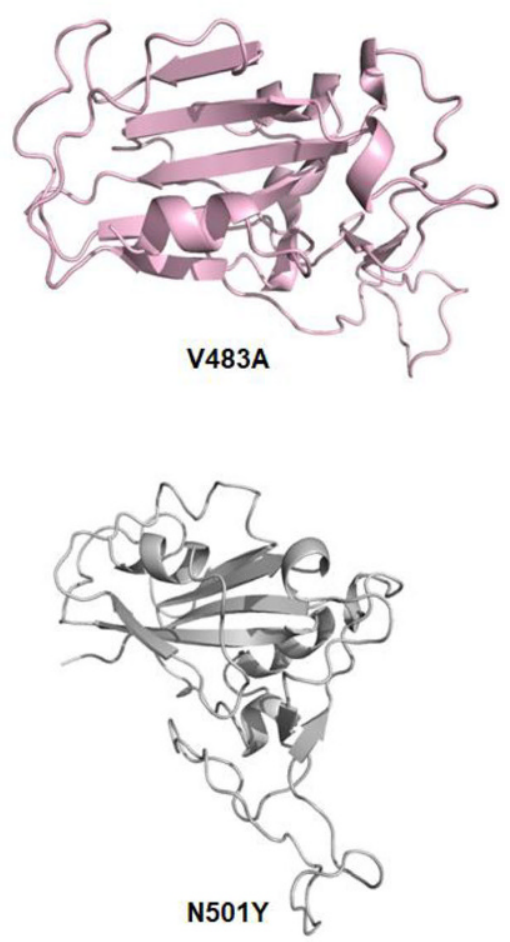

Fig. 4 Protein-protein interaction analyses of a ACE2 and spike S1 V483A mutant complex and b ACE2 and spike S1 N501Y mutant complex ACE2 is shown in publication cartoon mode while V483A and N501Y mutants are shown in salmon and grey color, respectively. Interacting residues are shown in stick with magenta color and H-bonds are shown in black color. Interacting residues of ACE2 and spike S1 residues are labelled in three letter amino acid codes with black and red color, respectively different spike mutant proteins suggest that mutated RBD interacts with greater binding affinity with ACE2 than wild type RBD. The SARS-CoV-2 spike S protein of mutant V367F formed 8-10H-bonds (hydrogen bonds) with host ACE2 receptor protein, mutant G476S formed 9-11 H-bonds, V483A mutant formed 7-8 H-bonds and N501Y formed 12-13 H-bonds with host ACE2 protein (Fig. 3 und 4). In contrast, SARSCoV-2 spike $S$ wild type protein formed only $5-6 \mathrm{H}-$ bonds with host ACE2 receptor (Fig. 3a). Maximum number of $\mathrm{H}$-bonds formed in all mutant ACE2 spike $\mathrm{S}$ complexes as compared to wild type complex suggest that mutants of spike $S$ protein bind to host ACE2 protein with maximum affinity. Moreover, N501Y mutant displays higher binding affinity as compared to wild type and other mutants (Fig. 4b). The above result indicates that mutant strains of SARS-CoV-2, particularly N501Y mutant have higher tendency to cause infection than wild type and also the chance of infections are more in diabetic persons as they express high numbers of ACE2 receptor protein.

\section{Top 10 COVID-19 infected countries with obesity prevalence}

Globally as on 10 January 2021 there have been $88,383,771$ confirmed cases and 1,919,126 deaths from COVID-19 [62]. The USA reported the highest COVID19 confirmed cases $(21,761,186)$ followed by India $(10,450,284)$ and Brazil $(8,013,708)$ and for deaths USA $(365,886)$ remain in the top position followed by Brazil $(201,460)$ and India $(150,999)$ [62]. The highest number of deaths are found in the USA and among the top 10 COVID-19 infected countries, the reason could be obesity as a major genesis of comorbidities where $37.3 \%$ of the total population are found under the category of obesity ([63]; Fig. 3). This could be the consequences of an inattentive medical condition in association with obesity and COVID-19 with respect to various commodities and clinical outcomes [31, $32,35,36,41-45]$. To date, numbers of deaths due to COVID-19 are observed to be increasing with respect to their countrywide obesity prevalence. As of 10 January 2021 based on the death rate due to COVID-19, countries with higher prevalence of obesity observed the higher number of deaths, i.e. USA, Brazil, United Kingdom (Fig. 5; [64]); however, countries like Russia, Spain and Germany where the obesity prevalence is 
Fig. 5 Worldwide top 10 countries with COVID19 confirmed cases and deaths including the obesity percentages (WHO COVID-19 [62]). Country (obesity \%, WHO 2017 [63]) (confirmed COVID19 cases) data are given in number of populations [64]

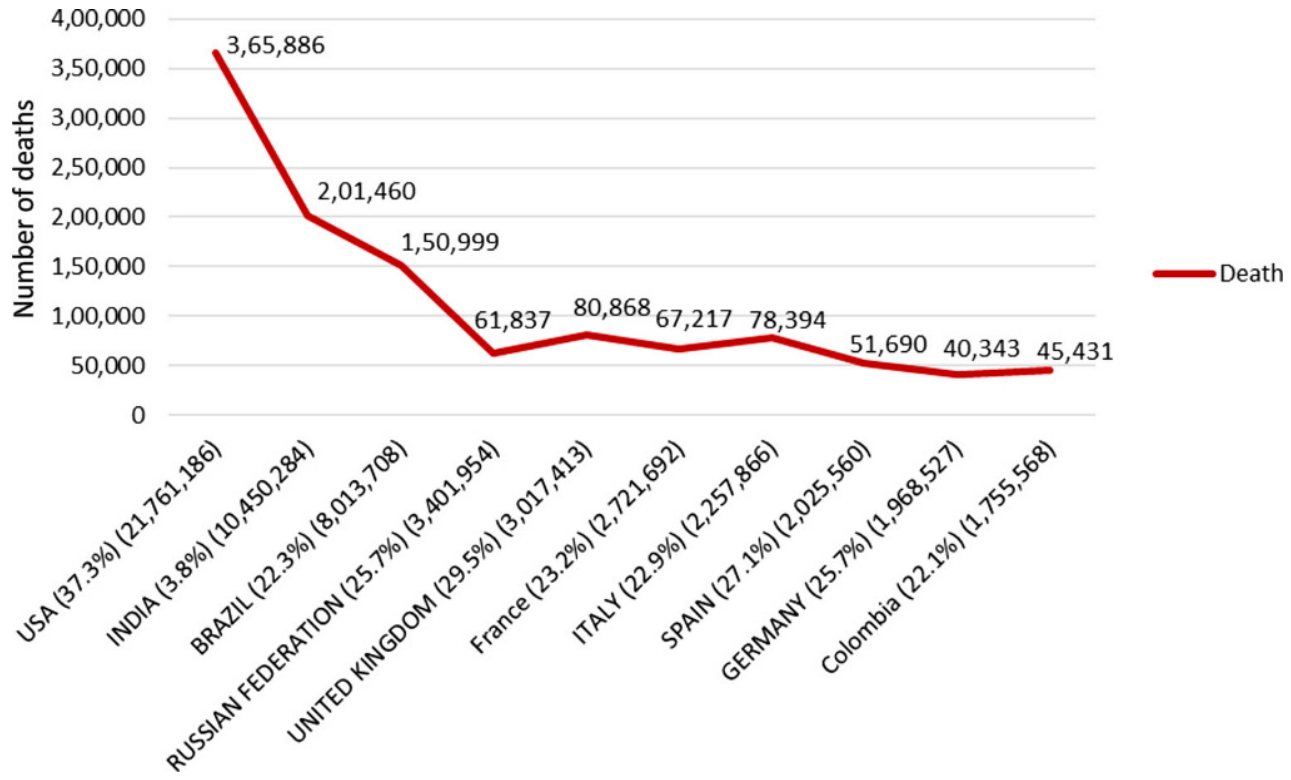

above $25 \%$ of the total population should take extra precaution for obese patients before facing such drastic health disaster.

COVID-19 may continue to spread throughout the world; there are very few countries which are not affected and this pandemic suggests the importance of investment in health systems, community-led response mechanism and need for preparedness and global health security [65]. Among various risk factors of COVID-19, it is unclear to show obesity as an independent risk factor, because of the paucity of research. Research findings from the different studies exhibit number of comorbidities are common between obesity and disease severity and death of the COVID-19 patients. In this review article obesity is confirmed as the independent risk factor for COVID19 because of the consistency of results found in different studies from various countries. In addition, countries with higher percentage of obesity observed to experience greatest number of death and disease severity, also countries with higher percentage of obesity and higher confirmed cases of COVID-19 should take precautions because the disease severity might be increased. Irrespective of the countries, obesity data, the finding of present review article suggests that obese patient and health workers, six types of organ diseases and five types of cancer patients should take maximum precautions and aggressive treatment in this present COVID-19 pandemic. Increased physical activity and regular exercise are positively correlated with improved metabolic outcomes and immunological health and reduce the risk of complications by modulating inflammation, augmenting the immune system and improving vaccination outcomes [66].

\section{Conclusion}

The present study indicates that mutant strains of SARS-CoV-2 are more infectious than wild type and that obese persons are more prone to infection as they have high ACE2 expression. Caloric restriction with regular exercise will help to improve the immunity of an individual to fight this present pandemic. And need more attention and aggressive treatment among the obese COVID-19 patients who were already been diagnosed with other diseases and cancer during this present scenario. Precaution is not only for the countries which have high prevalence of obesity; other countries with lower obesity prevalence should also take special precautions for those obese COVID19 patients. Finally, an extensive research is important to further elucidate the underlying mechanism of COVID-19 and obesity for the improvement of treatment and precaution.

Acknowledgements Indian Council of Medical Research (ICMR) New Delhi is duly acknowledged for financial support.

Author Contribution Conceptualization and idea: Somorjit Singh Ningombam and Pranay Tanwar. Methodology, literature search, analysis and investigation: Somorjit Singh Ningombam, Rakesh Kumar. Writing review and editing: Somorjit Singh Ningombam, Rakesh Kumar and Pranay Tanwar. Supervision: Pranay Tanwar. Pranay Tanwar and Somorjit Singh Ningombam contributed to critically revised the work. All authors approved the final manuscript as submitted and agree to the accountability for all aspects of the work.

Conflict of interest S. S. Ningombam, R. Kumar and P. Tanwar declare that they have no competing interests. 


\section{References}

1. BanerjeeA, Kulcsar K, Misra V, Frieman M, Mossman K. Bats and coronaviruses. Viruses. 2019;11:41. https://doi.org/ $10.3390 / \mathrm{vl} 1010041$.

2. Schoeman D, Fielding BC. Coronavirus envelope protein: current knowledge. Virol J. 2019;16:69. https://doi.org/10. 1186/s12985-019-1182-0.

3. Zumla A, Hui DS, Perlman S. Middle east respiratory syndrome. Lancet. 2015;386:995-1007. https://doi.org/10. 1016/S0140-6736(15)60454-8.

4. Cohen J, Normile D. New SARS-like virus in China triggers alarm. Science. 2020;367:234-5. https://doi.org/10.1126/ science.367.6475.234.

5. Zhu N, Zhang D, Wang W, Li X, Yang B, Song J, et al. A novel coronavirus from patients with pneumonia in China. N Engl J Med. 2020;382:727-33. https://doi.org/10.1056/ NEJMoa2001017.

6. Li Q, Guan X, Wu P, Wang X, Zhou L, Tong Y, et al. Early transmission dynamics in Wuhan, China, of novel coronavirus-infected pneumonia. N Engl J Med. 2020;382:1199-207. https://doi.org/10.1056/ NEJMoa2001316.

7. Chen Y, Liu Q, Guo D. Emerging coronaviruses: genome structure, replication, and pathogenesis. J Med Virol. 2020;92:418-23. https://doi.org/10.1002/jmv.25681.

8. Zhang N, Wang L, Deng X, Liang R, Su M, He C, et al. Recent advances in the detection of respiratory virus infection in humans. J Med Virol. 2020;92:408-17. https://doi.org/10. 1002/jmv.25674.

9. Chan JF, KokKH, Zhu Z, Chu H, To KK, Yuan S, etal. Genomic characterization of the2019novelhuman-pathogeniccoronavirus isolated from a patient with atypical pneumonia after visiting Wuhan. Emerg Microbes Infect. 2020;9:221-36. https://doi.org/10.1080/22221751.2020.1719902.

10. Cox RM, Wolf JD, Plemper RK. Therapeutically administered ribonucleoside analogue MK-4482/EIDD-2801 blocks SARS-CoV-2 transmission in ferrets. Nat Microbiol. 2020;3:1-8. https://doi.org/10.1038/s41564-020-00835-2.

11. Tong S, Su Y, Yu Y, Wu C, Chen J, Wang S, et al. Ribavirin therapy for severe COVID-19: a retrospective cohort study. Int J Antimicrob Agents. 2020;56:106114. https://doi.org/ 10.1016/j.ijantimicag.2020.106114.

12. Mantlo E, Bukreyeva N, Maruyama J, Paessler S, Huang C. Antiviral activities of type I interferons to SARS-CoV-2 infection. Antiviral Res. 2020;29:104811. https://doi.org/ 10.1016/j.antiviral.2020.104811.

13. Hong SI, Ryu BH, Chong YP, Lee S, Kim S, Kim HC, et al. Five severe COVID-19 pneumonia patients treated with triple combination therapy with lopinavir/ritonavir, hydroxychloroquine, and interferon $\beta$ - $1 \mathrm{~b}$. Int J Antimicrob Agents. 2020; https://doi.org/10.1016/j.ijantimicag.2020. 106052.

14. Polack FP, Thomas SJ, Kitchin N, Absalon J, Gurtman A, LockhartS, et al. Safety and efficacy of the BNT162b2 mRNA Covid-19 vaccine. N Engl J Med. 2020; https://doi.org/10. 1056/NEJMoa2034577.

15. Rose PW, Beran B, Bi C, Bluhm WF, Dimitropoulos D, Goodsell DS, et al. The RCSB Protein Data Bank: redesigned web site and web services. Nucleic Acids Res. 2010;39:D392-D401. https://doi.org/10.1093/nar/ gkq1021.

16. Yan R, Zhang Y, Li Y, Xia L, Guo Y, Zhou Q. Structural basis for the recognition of SARS-CoV-2 by full-length human ACE2. Science. 2020;367:1444-8. https://doi.org/10.1126/ science.abb2762.
17. Kozakov D, Hall DR, Xia B, Porter KA, Padhorny D, Yueh C, et al. The ClusPro web server for protein-protein docking. Nat Protoc. 2017;12:255-78. https://doi.org/10.1038/ nprot.2016.169.

18. Kumar R, Saran S. Structure, molecular dynamics simulation, and docking studies of Dictyostelium discoideum and human STRAPs. JCell Biochem. 2018;119:7177-91.https:// doi.org/10.1002/jcb.26840.

19. Guex N, Peitsch MC. SWISS-MODEL and the Swiss-Pdb Viewer: an environment for comparative protein modeling. Electrophoresis. 1997;18:2714-23. https://doi.org/10 1002/elps.1150181505.

20. Wu Z, McGoogan JM. Characteristics of and important lessons from the coronavirus disease 2019 (COVID-19) outbreakin China: summary of a report of 72314 cases from the Chinese Center for Disease Control and Prevention. JAMA. 2020;323:1239-42. https://doi.org/10.1001/jama. 2020.2648.

21. Bhatraju PK, Ghassemieh BJ, Nichols M, Kim R, Jerome KR, Nalla AK, et al. Covid-19 in critically ill patients in the Seattle region-case series. N Engl J Med. 2020;382:2012-22. https://doi.org/10.1056/NEJMoa2004500.

22. Stefan N, Birkenfeld AL, Schulze MB, Ludwig DS. Obesity and impaired metabolic health in patients with COVID-19. Nat RevEndocrinol. 2020;23:1-2. https://doi.org/10.1038/ s41574-020-0364-6.

23. Cai Q, Chen F, Wang T, Luo F, Liu X, Wu Q, et al. Obesity and COVID-19 severity in a designated hospital in Shenzhen, China. Diabetes Care. 2020; https://doi.org/10.2139/ssrn. 3556658.

24. Petrilli CM, Jones SA, Yang J, Rajagopalan H, O'Donnell LF, Chernyak Y, Tobin K, Cerfolio RJ, Francois F, Horwitz LI. Factors associated with hospitalization and critical illness among 4,103 patients with COVID-19 disease in New York City. MedRxiv. 1. 2020. https://doi.org/10.1101/2020.04. 08.20057794

25. Simonnet A, Chetboun M, Poissy J, Raverdy V, Noulette J, Duhamel A, et al. High prevalence of obesity in severe acute respiratory syndrome coronavirus-2 (SARS-CoV-2) requiring invasive mechanical ventilation. Obesity. 2020; https://doi.org/10.1002/oby.22831.

26. Lighter J, Phillips M, Hochman S. Obesity in patients younger than 60 years is a risk factor for COVID-19 hospital admission. Clin Infect Dis. 2020; https://doi.org/10. 1093/cid/ciaa415.

27. Zheng KI, Gao F, Wang XB, Sun QF, Pan KH, Wang TY, et al. Obesity as a risk factor for greater severity of COVID19 in patients with metabolic associated fatty liver disease. Metabolism. 2020;108:154244. https://doi.org/10.1016/j. metabol.2020.154244.

28. Zhou YJ, Zheng KI, Wang XB, Yan HD, Sun QF, Pan KH, et al. Younger patients with MAFLD are at increased risk of severe COVID-19 illness: a multicenter preliminary analysis. J Hepatol. 2020; https://doi.org/10.1016/j.jhep. 2020.04 .027$.

29. Huang JF, WangXB, Zheng KI, Liu WY, Chen JJ, George J, et al. Obesity hypoventilation syndrome and severe COVID-19. Metabolism. 2020;108:154249. https://doi.org/10.1016/j. metabol.2020.154249.

30. Bello-Chavolla OY, Bahena-LopezJP, Antonio-Villa NE, Vargas-Vázquez A, González-Díaz A, Márquez-Salinas A, Fermín-Martínez CA, Naveja JJ, Aguilar-Salinas CA. Predicting mortality due to SARS-CoV-2: A mechanistic score relating obesity and diabetes to COVID-19 outcomes in Mexico. MedRxiv.1. 2020. https://doi.org/10.1101/2020.04.20. 20072223. 
31. Murugan AT, Sharma G. Obesity and respiratory diseases. Chronic Respir Dis. 2008;5:233-42. https://doi.org/10. $1177 / 1479972308096978$.

32. Li J, Lai D, Wu D. Laparoscopic Roux-en-Y gastric bypass versus laparoscopic sleeve gastrectomy to treat morbid obesity-related comorbidities: a systematic review and meta-analysis. OBES SURG. 2016;26:429-42. https://doi. org/10.1007/s11695-015-1996-9.

33. Kyrou I, Randeva HS, Tsigos C, Kaltsas G, Weickert MO. Clinical problems caused by obesity. Endotext [Internet]. South Dartmouth (MA): MDtext.com. 2018. https://www. ncbi.nlm.nih.gov/books/NBK278973/. PMID: 25905207.

34. Polovina S, Micić D, Bjelović M, Šumarac-Dumanović M, KendereškiA. Metabolic surgery and obesity related comorbidities. Vojnosanit Pregl. 2018;75:213-8. https://doi.org/ 10.2298/VSP160508340P

35. Scott HA, Wood LG, Gibson PG. Role of obesity in asthma: mechanisms and management strategies. Curr Allerg Asthma Rep. 2017;17:53. https://doi.org/10.1007/s11882017-0719-9.

36. Nigatu YT, Reijneveld SA, de Jonge P, van Rossum E, Bültmann U. The combined effects of obesity, abdominal obesity and major depression/anxiety on health-related quality of life: the lifelines cohort study. PLoS ONE. 2016;11:e148871. https://doi.org/10.1371/journal.pone. 0148871.

37. Upadhyay J, Farr O, Perakakis N, Ghaly W, Mantzoros C. Obesity as a disease. Med Clin. 2018;102:13-33.https:// doi. org/10.1016/j.mcna.2017.08.004.

38. Fontaine KR, Redden DT, Wang C, Westfall AO, Allison DB. Years of life lost due to obesity. JAMA. 2003;289:187-93. https://doi.org/10.1001/jama.289.2.187.

39. Peeters A, Barendregt JJ, Willekens F, Mackenbach JP, Al Mamun A, Bonneux L. Obesity in adulthood and its consequences for life expectancy: a life-table analysis. Ann Intern Med. 2003;138:24-32. http://www.ncbi.nlm.nih. gov/htbin-post/Entrez/query?.

40. Narayan KM, Boyle JP, Thompson TJ, Sorensen SW, Williamson DF. Lifetime risk for diabetes mellitus in the United States. JAMA. 2003;290:1884-90. https://doi.org/ 10.1001/jama.290.14.1884.

41. Grover SA, Kaouache M, Rempel P, Joseph L, Dawes M, Lau DC, et al. Years of life lost and healthy life-years lost from diabetes and cardiovascular disease in overweight and obese people: a modelling study. Lancet Diab Endocrinol. 2015;3:114-22. https://doi.org/10.1016/S22138587(14)70229-3.

42. Peng YD, Meng K, Guan HQ, Leng L, Zhu RR, Wang BY, et al. Clinical characteristics and outcomes of 112 cardiovascular disease patients infected by 2019-nCoV. Zhonghua Xin Xue Guan Bing Za Zhi. 2020;48:E4. https://doi.org/10.3760/ cma.j.cn112148-20200220-00105.

43. YangJ, Zheng Y, Gou X, Pu K, Chen Z, Guo Q, etal. Prevalence of comorbidities in the novel Wuhan coronavirus (COVID19) infection: a systematic review and meta-analysis. Inter J Infect Dis. 2020;94:91-5. https://doi.org/10.1016/j.ijid. 2020.03 .017$.

44. Liang W, Guan W, Chen R, Wang W, Li J, Xu K, et al. Cancer patients in SARS-CoV-2 infection: a nationwide analysis in China. Lancet Oncol. 2020;21:335-7. https://doi.org/10. 1016/S1470-2045(20)30096-6.

45. Halpin DM, Faner R, Sibila O, Badia JR, Agusti A. Do chronic respiratory diseases or their treatment affect the risk of SARS-CoV-2 infection? Lancet Respir Med. 2020;8:436-8. https://doi.org/10.1016/S2213-2600(20)30167-3.

46. Fadini GP, Morieri ML, Longato E, Avogaro A. Prevalence and impact of diabetes among people infected with SARS-
CoV-2. JEndocrinol Invest. 2020;43:867-9. https:// doi.org/ 10.1007/s40618-020-01236-2.

47. YangX, YuY,XuJ, ShuH, LiuH, WuY, etal. Clinical courseand outcomes of critically ill patients with SARS-CoV-2 pneumonia in Wuhan, China: a single-centered, retrospective, observational study. Lancet Respir Med. 2020;8:475-81. https://doi.org/10.1016/S2213-2600(20)30079-5.

48. Zheng YY, Ma YT, Zhang JY, Xie X. COVID-19 and the cardiovascular system. Nat Rev Cardiol. 2020;17:259-60. https://doi.org/10.1038/s41569-020-0360-5.

49. Jia X, Yin C, Lu S, Chen Y, Liu Q, Bai J, et al. Two Things about COVID-19 Might Need Attention. Preprints 2020, 2020020315. https://doi.org/10.20944/preprints202002. 0315.v1.

50. Zou X, Chen K, Zou J, Han P, Hao J, Han Z. Single-cell RNAseq data analysis on the receptor ACE2 expression reveals the potential risk of different human organs vulnerable to 2019-nCoVinfection. Front Med. 2020;14:185-92. https:// doi.org/10.1007/s11684-020-0754-0.

51. Ouchi N, Parker JL, Lugus JJ, Walsh K. Adipokines in inflammation and metabolic disease. Nat Rev Immunol. 2011;11:85-97. https://doi.org/10.1038/nri2921.

52. Ahn SY, Sohn SH, Lee SY, Park HL, Park YW, Kim H, et al. The effect of lipopolysaccharide-induced obesity and its chronic inflammation on influenza virus-related pathology. Environ Toxicol Pharmacol. 2015;40:924-30. https:// doi.org/10.1016/j.etap.2015.09.020.

53. Karlsson EA, Hertz T, Johnson C, Mehle A, Krammer F, Schultz-Cherry S. Obesity outweighs protection conferred by adjuvanted influenza vaccination. mBio. 2016;7:e1144-e1116. https://doi.org/10.1128/mBio. 01144- 16 .

54. Xue KS, Stevens-Ayers T, Campbell AP, Englund JA, Pergam SA, Boeckh $\mathrm{M}$, et al. Parallel evolution of influenza across multiple spatiotemporal scales. Elife. 2017;6:e26875. https://doi.org/10.7554/eLife.26875.

55. Zheng Q, Cui G, Chen J, Gao H, Wei Y, Uede T, et al. Regular exercise enhances the immune response against microbial antigens through up-regulation of toll-like receptor signaling pathways. Cell Physiol Biochem. 2015;37:735-46. https://doi.org/10.1159/000430391.

56. Reidy PT, Yonemura NM, Madsen JH, McKenzie AI, Mahmassani ZS, Rondina MT, et al. An accumulation of muscle macrophages is accompanied by altered insulin sensitivity after reduced activity and recovery. Acta Physiol. 2019;226:e13251. https://doi.org/10.1111/apha.13251.

57. Maier HE, Lopez R, Sanchez N, Ng S, Gresh L, Ojeda S, et al. Obesity increases the duration of influenza a virus shedding in adults. J Infect Dis. 2018;218:1378-82. https://doi.org/ 10.1093/infdis/jiy370.

58. Honce R, Karlsson EA, Wohlgemuth N, Estrada LD, Meliopoulos VA, Yao J, et al. Obesity-related microenvironment promotes emergence of virulent influenza virus strains. mBio. 2020;11:e3341. https://doi.org/10.1128/ mBio.03341-19.

59. Yang J, Zheng Y, GouX, Pu K, Chen Z, Guo Q, et al. Prevalence of comorbidities in the novel Wuhan coronavirus (COVID19) infection: a systematic review and meta-analysis. Intern J Infect Dis. 2020;94:91-5. https://doi.org/10.1016/j.ijid. 2020.03.017.

60. Korber B, Fischer W, Gnanakaran SG, Yoon H, Theiler J, Abfalterer W, et al. Spike mutation pipeline reveals the emergence of a more transmissible form of SARS-CoV-2. BioRxiv. 2020; https://doi.org/10.1101/2020.04.29.069054.

61. Lan J, Ge J, Yu J, Shan S, Zhou H, Fan S, et al. Structure of the SARS-CoV-2 spike receptor-binding domain bound to the 
ACE2 receptor. Nature. 2020;581:215-20. https://doi.org/ 10.1038/s41586-020-2180-5.

62. WHO. Coronavirus disease2019 (COVID-19).2019. https:// www.who.int/emergencies/diseases/novel-coronavirus2019. Accessed 11 Jan 2020.

63. WHO. Global Health Observatory (GHO) data. 2017. https://www.who.int/gho/ncd/risk_factors/overweight/ en/. Accessed 11 Jan 2020.

64. https://www.worldometers.info/coronavirus/. Accessed: 09.02.2021

65. Chatterjee P, Nagi N, Agarwal A, Das B, Banerjee S, Sarkar S, et al. The 2019 novel coronavirus disease (COVID-19) pandemic: a review of the current evidence. Indian J Med Res. 2020;151:147. https://doi.org/10.4103/ijmr.IJMR_ 519_20.

66. Choon Lim Wong G, Narang V, Lu Y, Camous X, Nyunt MS, Carre C, et al. Hallmarks of improved immunological responses in the vaccination of more physically active elderly females. Exerc Immunol Rev. 2019;25:20-33.

Publisher's Note Springer Nature remains neutral with regard to jurisdictional claims in published maps and institutional affiliations. 